\title{
C-5 palsy after cerebrospinal fluid diversion in posttraumatic syringomyelia: case report
}

\author{
George M. Ghobrial, MD, Sara Beygi, MD, Matthew J. Viereck, Joshua E. Heller, MD, \\ Ashwini Sharan, MD, Jack Jallo, MD, PhD, James S. Harrop, MD, and Srinivas Prasad, MD \\ Department of Neurological Surgery, Thomas Jefferson University Hospital, Philadelphia, Pennsylvania
}

\begin{abstract}
Syringomyelia is a potentially debilitating disease that involves abnormal CSF flow mechanics; its incidence after traumatic spinal cord injury (SCI) is approximately $15 \%$. Treatment consists of restoration of CSF flow, typically via arachnoidolysis and syrinx decompression. The authors present a case of pronounced syringomyelia in a patient with concomitant severe cervical myelomalacia to demonstrate unilateral C-5 palsy as a potential complication of aggressive syrinx decompression at a remote level.
\end{abstract}

A 56-year-old man with a remote history of SCI at T-11 (ASIA [American Spinal Injury Association] Grade A) presented with complaints of ascending motor and sensory weakness into the bilateral upper extremities that had progressed over 1 year. MRI demonstrated severe distortion of the spinal cord at the prior injury level of T10-11, where an old anterior column injury and prior hook-rod construct was visualized. Of note, the patient had a holocord syrinx with demonstrable myelomalacia. To restore CSF flow and decompress the spinal cord, T-2 and T-3 laminectomies, followed by arachnoidolysis and syringopleural shunt placement, were performed. Postoperatively on Day 1 , with the exception of a unilateral deltoid palsy, the patient had immediate improvement in upper-extremity strength and myelopathy. He was discharged from the hospital on postoperative Day 5; however, at his 2-week follow-up visit, a persistent unilateral deltoid palsy was noted. MRI demonstrated a significant reduction in the holocord syrinx, no neural foraminal stenosis, and a significant positional shift of the ventral spinal cord. Further motor recovery was noted at the 8-month follow-up.

Syringomyelia is a debilitating disease arising most often as a result of traumatic $\mathrm{SCl}$. In the setting of myelomalacia with a pronounced syrinx, C-5 palsy is a potential complication of syrinx decompression.

http://thejns.org/doi/abs/10.3171/2014.10.SPINE14315

KEY WORDS C-5 palsy; deltoid palsy; syringomyelia; syringopleural shunt; cervical spine

$\mathrm{C}$

-5 palsy results in deltoid weakness, a disabling and recognized complication of cervical spine decomtossion, which manifests as an inability to perform daily tasks such as grooming and feeding due to the loss of arm abduction. The diagnosis of C-5 palsy is apparently a nebulous one, owing to the variability in diagnostic technique and criteria in the literature, and the reported postoperative incidence ranges from $0 \%$ to $30 \% .{ }^{3}$ Many of the large series to date place the incidence of isolated C-5 palsy closer to 5\%-6.7\%. ${ }^{2,5}$ Bilateral C-5 palsy is less common, with a reported incidence of less than $1 \%{ }^{2}$
Most recently, in a large surgical series of cervical decompression by Nassr and colleagues, ${ }^{5}$ the relative incidence of unilateral C-5 palsy was reported to be $9.1 \%$ in association with cervical laminectomy and fusion; the incidence associated with ventral approaches ranged from $5 \%$ to $8.4 \%$; and the incidence associated with laminoplasty, the lowest, was $4.8 \%$. These results were further supported by those of Bydon and colleagues, who found that posterior decompression carried a significantly higher risk of C-5 palsy than ventral decompression ( $14.5 \%$ vs $2.4 \%$, respectively). ${ }^{2}$ The mechanism of $\mathrm{C}-5$ palsy is not com-

ABBREVIATION SCI = spinal cord injury.

SUBMITTED March 25, 2014. ACCEPTED October 7, 2014.

INCLUDE WHEN CITING Published online February 6, 2015; DOI: 10.3171/2014.10.SPINE14315.

DISCLOSURE Dr. Sharan reports the following: clinical or research support for study described (includes equipment or material) from Medtronic and St. Jude Medical; consultant, Medtronic; ownership, ICP; ownership, ICVRx; ownership, TigerLabs; honorarium, St. Jude Medical. Dr. Harrop reports the following: consultant, DePuy Spine; consultant, Bioventus; and consultant, Teijin. 
pletely understood, but it is attributed to C-5 nerve root impingement at the neural foramen, which is exacerbated by spinal cord migration that occurs after decompression.

We present the first case in the literature to date of C-5 palsy resulting from the remote decompression of a holocord syrinx with a syringopleural shunt.

\section{Case Report}

Presentation and Examination

A 56-year-old man with a remote history of spinal cord injury (SCI) at T-11 (ASIA [American Spinal Injury Association] Grade A) presented with a pattern of progressive, ascending sensory and motor deficits. Specifically, he had complained of a loss of hand dexterity and bilateral upper-extremity weakness. His preoperative deltoid weakness was a motor Grade 4+/5 and 4-/5 on the left and right sides, respectively. Distally on the left side a motor weakness of Grade 4/5 was found. On the right side, he had a distal motor score of $4 / 5$, with Grade 2/5 hand intrinsic weakness. No motor or sensory dysfunction was noted in his lower extremities. Hyperreflexia was noted in the bilateral upper extremities. An MRI study demonstrated a large holocord syrinx spanning from the cervicomedullary junction to T-10 (Fig. 1). Severe cervical myelomalacia was noted without significant spinal canal stenosis (Fig. 2). A chronic healed burst fracture at T-10 and T-11 was noted, with a resultant kyphotic deformity. Also, a hook-rod construct spanning T7-12 was evident (Fig. 1). The site of the T-11 SCI marked the caudal extent of the syrinx.

\section{Operation}

A T2-3 laminectomy was performed, followed by a midline myelotomy. Brisk CSF was encountered on entering the syrinx, whereupon a T-shaped catheter was deployed rostrally and caudally into the syrinx cavity. Neuromonitoring noted no lower-extremity signals. Transient decreases in the sensory amplitudes were observed during dorsal column incision and catheter manipulation and motor evoked potentials were stable. No motor changes were noted throughout the operation. The catheter was then subcutaneously tunneled to the midscapular level of the third rib and into the pleural space under direct visualization.

\section{Postoperative Course}

The patient had a delayed right deltoid palsy, which was still present at his 2 -week follow-up visit. At that time, interim MRI demonstrated a considerable collapse of the holocord syrinx, as well as increased circumferential CSF signal (Fig. 3). MRI at 1 month postoperatively showed further collapse of the spinal cord, illustrating the extensive cervical and thoracic myelomalacia caused by the syrinx (Fig. 4).

Electromyography and nerve conduction velocity conducted at the 3-month follow-up visit were further supportive of a diagnosis of an isolated C-5 palsy. In the right C-5 nerve root distribution a significant peripheral nerve root lesion was noted. The remaining proximal upper-extremity nerve distributions were symmetric. The patient went on to demonstrate further motor recovery of greater than Grade 3/5 in the deltoid muscle group.

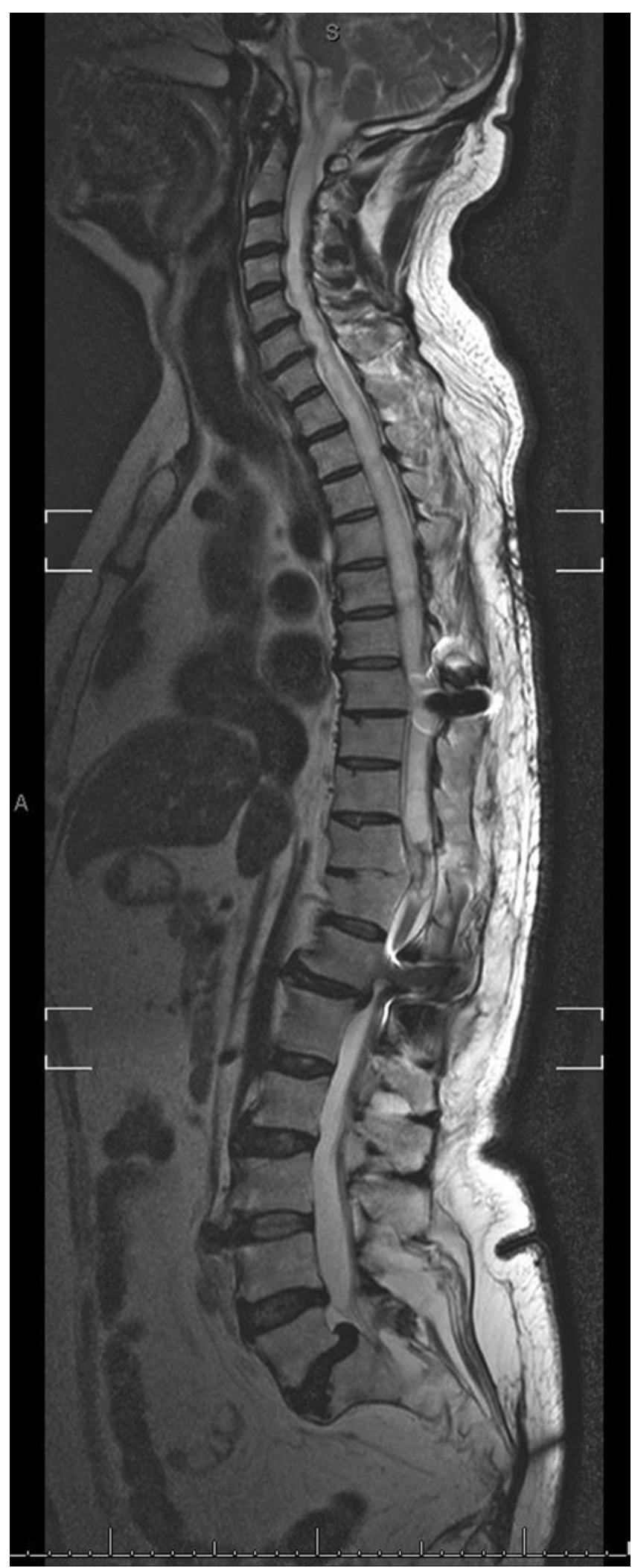

FIG. 1. Sagittal T2-weighted MR image, scout view, of the neuraxis demonstrating a pronounced holocord syrinx extending from the cervicomedullary junction to the level of prior injury at T10-11. A prior hookrod construct can be visualized from T-7 to T-12. 

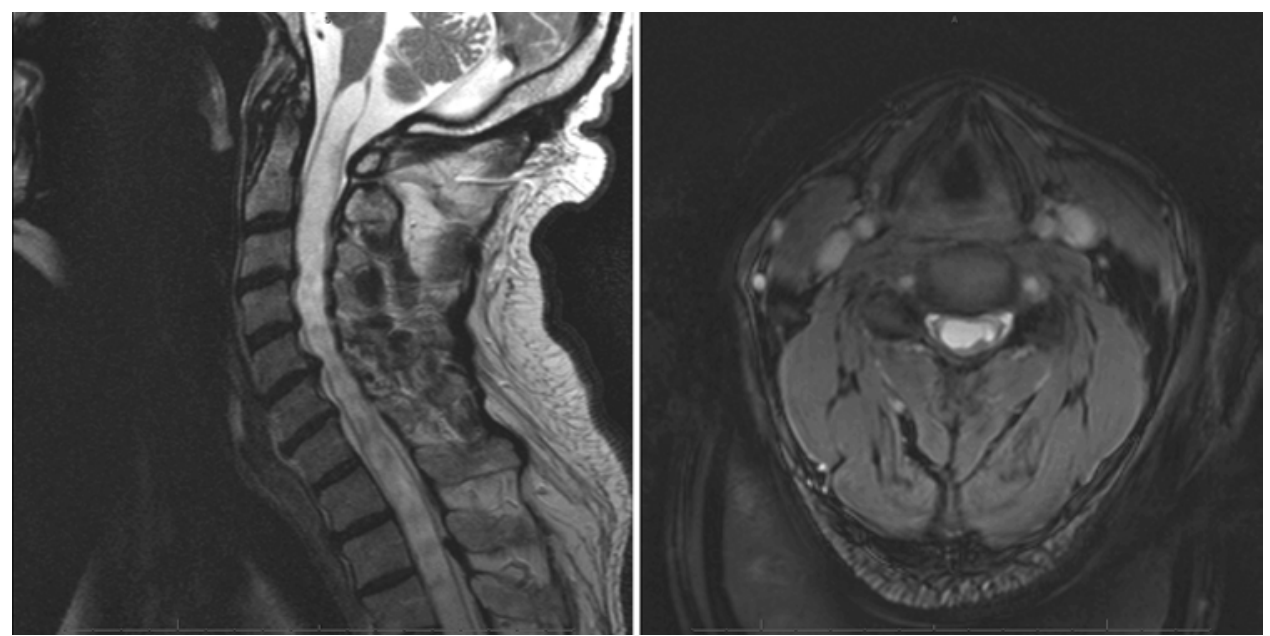

FIG. 2. Sagittal (left) and axial (right) C4-5 T2-weighted MR images demonstrating a holocord syrinx with significant myelomalacia.

\section{Discussion}

To our knowledge, C-5 palsy as a consequence of syrinx decompression has not been previously reported, likely because of the low disease prevalence combined with the lower number of patients encountered with severe myelomalacia with a holocord syrinx. ${ }^{4}$ Nonetheless, a significant morbidity affected our patient, who, despite having progressive ascending myelopathy, did not have prior deltoid weakness. His prognosis for recovery is good, as prior reports show that up to $70 \%$ of individuals have complete spontaneous improvement without the need for treatment at 5 months. ${ }^{3}$

As to the mechanism of our patient's injury, the absence of foraminal stenosis and prior cervical surgery suggests an alternate explanation for what is typically seen after posterior cervical decompression. In the presence of severe myelomalacia and a distended syrinx, we believe there was critical traction on the $\mathrm{C}-5$ nerve root re- sulting from a positional change after surgery. Moreover, when comparing preoperative (Fig. 2) and postoperative (Figs. 3 and 4) axial imaging, dorsal shift of the cervical spinal cord was noted maximally at the C4-5 level. A relationship between dorsal cervical cord drift and C-5 palsy has been previously correlated in radiographic studies, showing the maximal cervical cord positional change at 24 hours after laminoplasty to be $2.8 \mathrm{~mm}$. A relative mean improvement of $1.9 \mathrm{~mm}$ is then typically observed by 2 weeks. ${ }^{7}$ Moreover, in the same study, in cases of C-5 palsy, dorsal displacement undergoes a greater positional change, drifting up to $5.5 \mathrm{~mm}$ whereby a decrease to about $3 \mathrm{~mm}$ can be seen at 2 weeks. ${ }^{7}$ The gradual ventral rebound may explain the typical improvement that is observed.

Aside from an increased situational awareness of the potential for cord drift, there are not many precautions one can take to avoid this. Dorsal displacement of the spinal cord after decompression in tandem with a tethered nerve
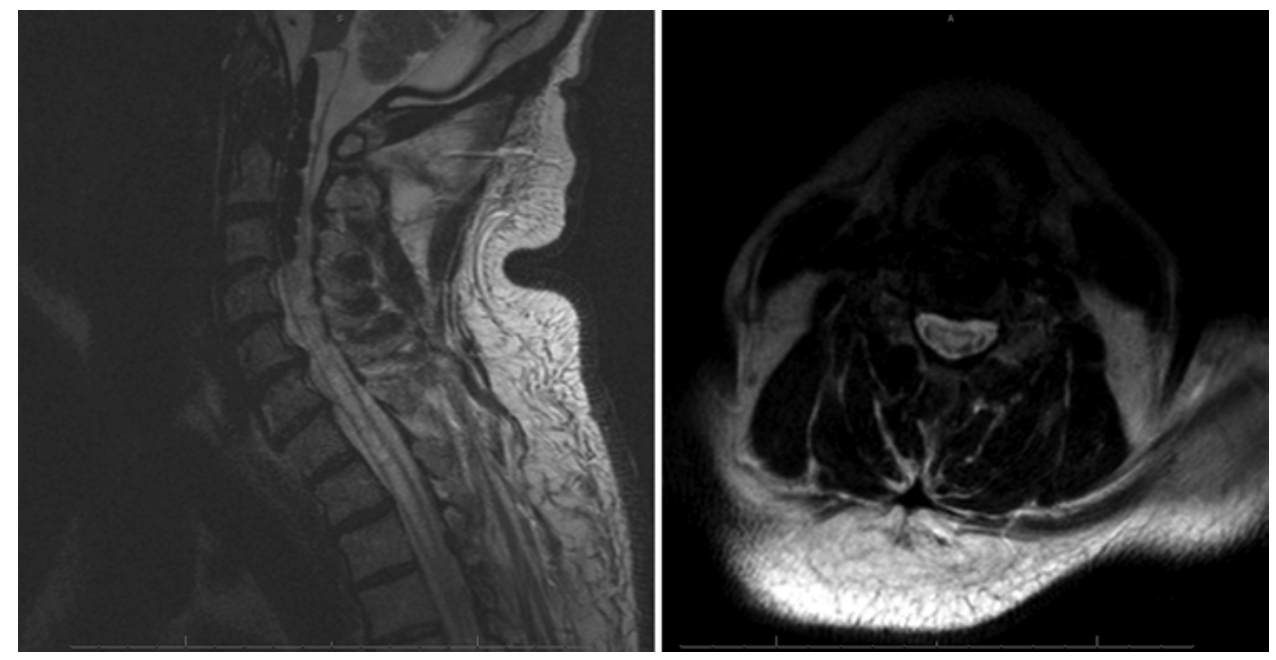

FIG. 3. Left: Sagittal T2-weighted MR image of the cervical spine 1 day postoperatively after the development of deltoid weakness. Considerable decrease in the holocord syrinx is noted, as is restoration in circumferential CSF flow. Right: Corresponding axial image at the level of $\mathrm{C} 4-5$ demonstrating no significant foraminal stenosis. 


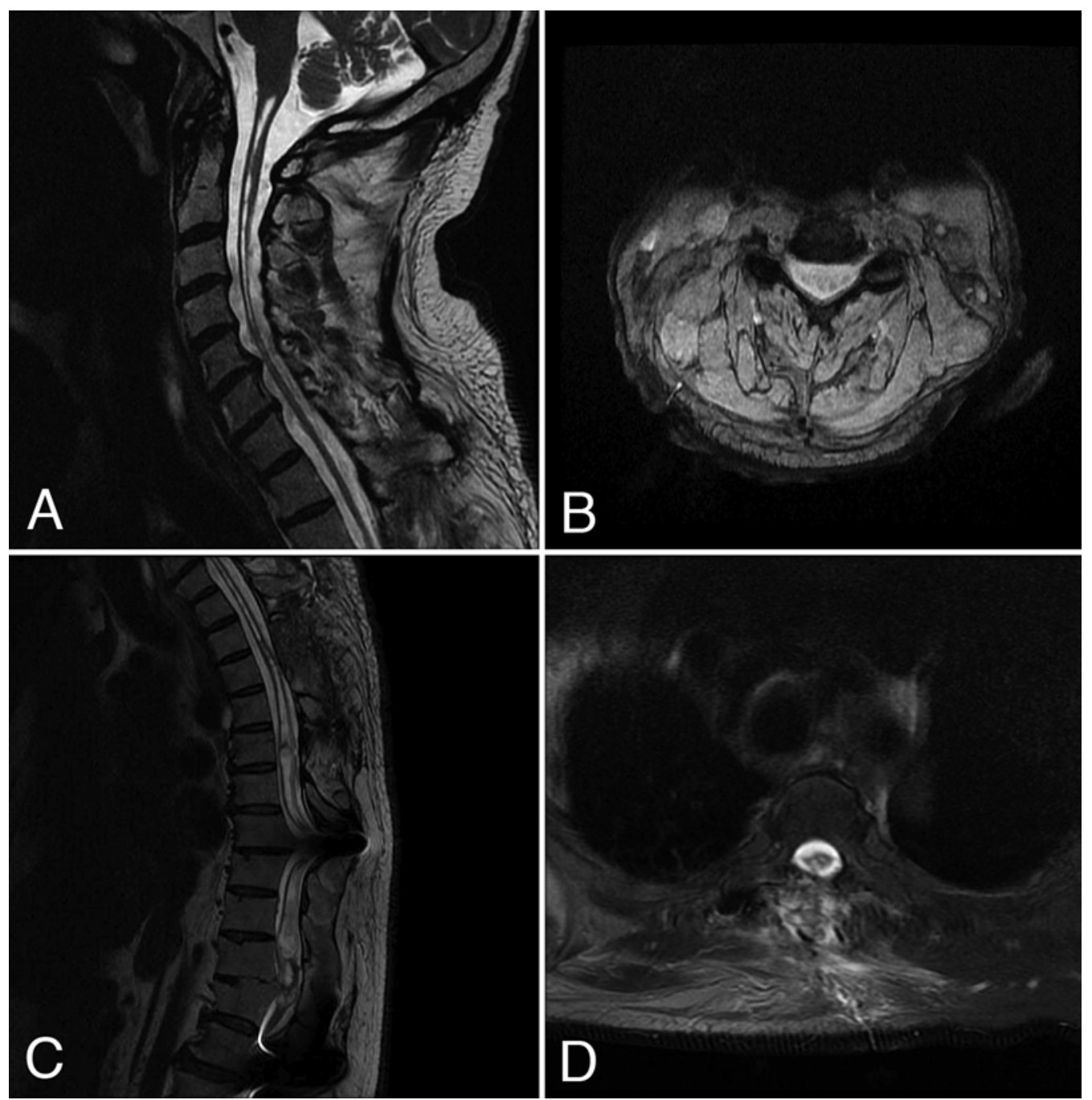

FIG. 4. Sagittal and axial T2-weighted MR images of the cervical spine (A and B, respectively) and corresponding images of the thoracic spine ( $\mathbf{C}$ and $\mathbf{D}$, respectively) demonstrating further collapse of the syrinx.

root at a narrow foramen can lead to symptomatic postoperative radiculopathy. Furthermore, systematic reviews of the literature find intraoperative neuromonitoring to be effective and reliable at detecting intraoperative C -5 palsy. However, this is not the rule, as we did not observe C-5 motor root changes throughout the case. Yet no specific preventative measure has been definitively proven to lower the risk of C-5 palsy. ${ }^{3}$

One further diagnostic consideration is that of Parsonage-Turner syndrome, or neuralgic amyotrophy. Classically, this diagnosis is heralded by the symptoms of suddenonset neuropathic pain followed by weakness within a few hours to several days. ${ }^{1,6}$ While the onset of weakness in Parsonage-Turner syndrome presents more commonly in a delayed fashion, this is not a definite finding and cannot be completely ruled out. The follow-up electromyography/ nerve conduction velocity studies obtained at 3 months are further supported by the diagnosis of C-5 palsy by motor and sensory conduction delay confined to the C-5 motor root. Typically in Parsonage-Turner syndrome the pain, sensory, and motor findings are not all confined to the same nerve distribution. ${ }^{8,9}$

\section{Conclusions}

Traumatic syringomyelia is a morbid disease carrying the risk of progressive neurological deterioration after SCI. In the setting of severe myelomalacia and a pronounced syrinx, aggressive CSF flow diversion can lead to substantial spinal cord decompression and drift. This report serves to raise awareness of the postoperative risk of C-5 palsy in the surgical treatment of syringomyelia, even when treated remotely in the thoracic spine.

\section{References}

1. Brown JM, Yee A, Ivens RA, Dribben W, Mackinnon SE: Post-cervical decompression parsonage-turner syndrome represents a subset of C5 palsy: six cases and a review of the literature: case report. Neurosurgery 67:E1831-E1844, 2010

2. Bydon M, Macki M, Kaloostian P, Sciubba DM, Wolinsky 
JP, Gokaslan ZL, et al: Incidence and prognostic factors of C5 palsy: a clinical study of 1,001 cases and review of the literature. Neurosurgery 74:595-605, 2014

3. Currier BL: Neurological complications of cervical spine surgery: C5 palsy and intraoperative monitoring. Spine (Phila Pa 1976) 37:E328-E334, 2012

4. Klekamp J: Treatment of posttraumatic syringomyelia. J Neurosurg Spine 17:199-211, 2012

5. Nassr A, Eck JC, Ponnappan RK, Zanoun RR, Donaldson WF III, Kang JD: The incidence of C5 palsy after multilevel cervical decompression procedures: a review of 750 consecutive cases. Spine (Phila Pa 1976) 37:174-178, 2012

6. Rubin DI: Neuralgic amyotrophy: clinical features and diagnostic evaluation. Neurologist 7:350-356, 2001

7. Shiozaki T, Otsuka H, Nakata Y, Yokoyama T, Takeuchi K, Ono A, et al: Spinal cord shift on magnetic resonance imaging at 24 hours after cervical laminoplasty. Spine (Phila Pa 1976) 34:274-279, 2009
8. van Alfen $\mathrm{N}$ : Clinical and pathophysiological concepts of neuralgic amyotrophy. Nat Rev Neurol 7:315-322, 2011

9. van Alfen N, van Engelen BG: The clinical spectrum of neuralgic amyotrophy in 246 cases. Brain 129:438-450, 2006

\section{Author Contributions}

Conception and design: Prasad. Acquisition of data: Beygi, Viereck. Drafting the article: Ghobrial. Critically revising the article: Prasad, Harrop. Reviewed submitted version of manuscript: Prasad, Ghobrial, Heller, Sharan, Jallo, Harrop. Study supervision: Prasad.

\section{Correspondence}

Srinivas Prasad, Department of Neurological Surgery, Thomas Jefferson University Hospital, 909 Walnut St., 3rd Fl.,

Philadelphia, PA 19107. email: srinivas.prasad@jefferson.edu. 